\title{
A SELETIVIDADE DO SISTEMA PENAL BRASILEIRO A PARTIR DE UMA EPISTEMOLOGIA FEMINISTA
}

\section{THE SELECTIVITY OF THE BRAZILIAN CRIMINAL SYSTEM FROM A FEMINIST EPISTEMOLOGY}

\author{
Jéssica Lemes Braz ${ }^{1}$ \\ Maxilene Soares Corrêa ${ }^{2}$
}

\begin{abstract}
Resumo: A presente pesquisa tem por objeto a análise da seletividade no sistema penal, com ênfase no encarceramento feminino. O trabalho partiu da epistemologia feminista, iniciando-se por uma abordagem do histórico do patriarcado existente em nossa sociedade e suas influências criminológicas. A questão que se buscou analisar foi o crescente encarceramento das mulheres, relacionando-o com a política proibicionista das drogas. $T$ rata-se de pesquisa qualiquantitativa, na qual se utilizou fontes bibliográficas, documentais e análise de estatísticas referentes às penitenciárias brasileiras colhidas das Informações Penitenciárias (INFOPEN) do ano de 2014. Para tanto, no primeiro momento, buscou-se tratar da opressão vivida pela mulher e do surgimento do feminismo como um mecanismo de libertação e luta para a garantia de direitos às mulheres. No segundo tópico pesquisou-se sobre a política proibicionista de drogas e seus efeitos no encarceramento feminino. No terceiro e último tópico, restou comprovado que o tráfico de drogas é o crime que mais encarcera mulheres no Brasil, e ainda traçou-se um perfil das mulheres presas, analisando os direitos que lhe são violados no cárcere. Por todos esses dados, compreende-se que a política proibicionista é ineficaz, e acaba evidenciando e fortalecendo a seletividade penal especialmente no que tange às mulheres.
\end{abstract}

Palavras-Chave: encarceramento feminino. tráfico de drogas. política proibicionista. gênero.

Abstract: The present research aims at the analysis of selectivity in the penal system, with emphasis on female incarceration. The work started from feminist epistemology, beginning with an approach to the history of patriarchy existing in our society and its criminological influences. The question that was sought to analyze was the growing incarceration of women, relating it to the prohibitionist policy of drugs. It is a qualitative research, in which bibliographical sources, documentaries and analysis of statistics related to Brazilian penitentiaries collected from the Penitentiary Information (INFOPEN) of the year 2014 were used. At that moment, the aim was to deal with the oppression experienced by and the emergence of feminism as a mechanism for liberation and struggle for the guarantee of women's rights. In the second topic we investigated the prohibitionist drug policy and its effects on female incarceration. In the third and last topic, it has been proven that drug trafficking is the crime that most imprisoned women in Brazil, and a profile of women prisoners has been traced, analyzing the rights that are violated in the prison. From all these data, it is understood that the prohibitionist policy is ineffective, and ends up evidencing and strengthening the criminal selectivity especially with regard to women.

Key words: female incarceration. drug trafficking. prohibitionist policy. genre.

\section{INTRODUÇÃO}

A opressão da mulher na sociedade se evidência pela sua exclusão nos direitos sociais, com o contrato familiar, mantendo a dominação econômicos e familiares. A submissão da mulher masculina, provocando uma violência psicológica ao homem é ainda hoje alarmante, corroborando a contra a mulher. Desse modo, os movimentos uma desigualdade de gênero.

Deste modo, no primeiro tópico, firmamos de direitos, em um sentido igualitário, podendo nosso referencial teórico no ideal de sociedade assim estabelecer uma harmonia nos direitos 17cadêmica do Curso de Direito Da Faculdade Evangélica de Goianésia - jessica-lemesb@hotmail.com
2Professor da Faculdade Evangélica de Goianésia - maxilene.scorrea@gmail.com 
jurídicos, políticos, familiares, sociais e econômicos entre homens e mulheres, rompendo os padrões estabelecidos em uma sociedade machista.

O papel da mulher como dona de casa, mãe de família e esposa, ganhou por um longo período o "ideal" na sociedade. As lutas sociais, em especial a luta do feminismo, procurou e ainda hoje procura no cenário mundial, a busca pela equidade de direitos e obrigações entre homens e mulheres. As lutas sociais ainda permanecem reivindicando e manifestando contra as disparidades de gênero.

Nesse sentido, o feminismo surgiu desde seus primórdios, como luta social, intencionando para a igualdade de gênero, pressionando as instituições estatais a considerar e criar novos mecanismos para os interesses das mulheres. Obtendo conquistas importantes, como direito ao voto, abertura para o mercado de trabalho e etc. e ainda hoje, busca reivindicações para o direito igualitário entre homens e mulheres.

No segundo tópico, o trabalho busca analisar, tomando como base a luta de classes e ideias feministas, os condicionantes que tendem a penalizar as mulheres no sistema penal. As mulheres são condenadas as penas privativas de liberdade no Brasil principalmente pelo crime de tráfico de drogas. Hoje no Brasil a mulher presa não goza de seus direitos previstos em lei e tendem a viver em condições precárias, sofrendo com o abandono familiar, distanciamento dos seus filhos, exposições a doenças, dentre outros problemas.

A política proibicionista de drogas é alvo de diversas discussões para os órgãos responsáveis. Tornando como adequado a cassação e punição daqueles que de algum modo garantem sua atividade, produzindo ou comercializando. O proibicionismo é pautado em cinco concepções ideológicas: práxis moralista, saúde pública, segurança pública, segurança nacional e proibicionismo militarista, corroborando crises no sistema penal, como o encarceramento em massa. No caso brasileiro, é notório os encarcerados serem compostos por minorias, como negros e mulheres. No caso das mulheres, se estabelecem por se submeterem aos interesses dos seus companheiros.

No terceiro tópico, tratou-se da condição da seletividade no sistema penal brasileiro que estabelece uma situação subalterna às mulheres. A mulher que vive hoje no cárcere privado se vê impossibilitada de uma possível ressocialização, é impedida de retornar à sociedade com uma perspectiva de vivência adequada para enfrentar problemas sociais, familiares e econômicos.

O trabalho busca a análise por meio de pesquisa bibliográfica, documental e análise de dados das Informações Penitenciárias (INFOPEN).

Tomando como análise os dados das Informações Penitenciárias (INFOPEN), o encarceramento mostra outro modo de violência para as mulheres, uma vez que são submetidas a abusos e humilhações quando estão condenadas ao regime fechado. Considerando um diagnóstico social dessas mulheres, verifica-se que ocupam a camada baixa da sociedade. Quando encarceradas não são garantidos seus direitos, tendo que viver em condições precárias e com pouca possibilidade de ressocialização. 


\section{O contrato sexual: as relações} sociais como relação de gênero e a opressão da mulher em uma sociedade androcêntrica

Quando falamos em contrato, inicialmente a primeira ideia histórica e política que surge, diz respeito aos escritos do contrato social, apresentado por Rousseau em 1762. Deste modo, sobreveio o que mais tarde a sociedade entendeu 35):

como uma forma de modelo de organização do Estado, sendo a família a primeira entidade em que o indivíduo era inserido, e ainda, a figura masculina do pai como sendo naturalmente o chefe da família.

É a família, portanto, o primeiro modelo das sociedades políticas; o chefe é a imagem do pai, o povo a imagem dos filhos, e havendo nascido todos livres e iguais, não alienam a liberdade a não ser em troca da sua utilidade. Toda a diferença consiste em que, na família, o amor do pai pelos filhos o compensa dos cuidados que estes lhe dão, ao passo que, no Estado, o prazer de comandar substitui o amor que o chefe não sente por seus povos (ROUSSEAU, 1762, p.32).

Assim, se desencadeou o modelo de patriarcado hoje existente. $\mathrm{Na}$ concepção que se tinha do contrato social apresentada como uma história de liberdade, a mulher, na realidade, não celebrava tal contrato, mas participava como objeto deste. Tal forma de organização da sociedade civil trazia a ideia de liberdade apenas para aquele que é considerado como o líder, nesse caso, o homem.

Desta forma, decorrente do primeiro contrato, surgiu o conceito do contrato sexual, se tratando este da realidade trazida por Rousseau em sua obra.
Naturalmente, a imposição do homem sujeitou a mulher, mantendo-a sobre a dominação masculina. Sendo assim, o pacto original é na realidade um contrato social/sexual porque os direitos políticos femininos estão intrinsecamente submissos aos homens.

Segundo o conceito de Pateman (1993, p. 34-

Contar a história do contrato sexual é mostrar como a diferença sexual, o que é ser "homem" ou "mulher", e a construção da diferença sexual enquanto diferença política são essenciais para a sociedade civil. O feminismo sempre se preocupou com a diferença sexual, e as feministas estão enfrentando agora um problema muito complexo. No patriarcado moderno, a diferença entre os sexos é apresentada como uma diferença essencialmente natural. $\mathrm{O}$ direito patriarcal dos homens sobre as mulheres é apresentado como um reflexo da própria ordem da natureza. Como as feministas devem, então, lidar com a diferença sexual. A resposta feminista adequada parece ser, então, lutar pela eliminação de todas as referências à diferença entre homens e mulheres na vida política; assim, por exemplo, todas as leis e políticas deveriam ser do "gênero neutro".

Neste interim, surge a mobilização feminina no empenho pela conquista da igualdade de direitos, desempenhando um papel fundamental na realidade que vivemos hoje. A equiparação legal entre homens e mulheres se normatizou com o advento da Constituição Federal de 1988 que tratou de erradicar as disparidades de gênero, afirmando que "homens e mulheres são iguais em direitos e obrigações". 
Para Christo (2001) a harmonia está em trabalho, a necessidade de mão de obra e a estabelecer direitos jurídicos, políticos e expansão da industrialização, que demandou a econômicos independente do gênero. Trata-se de necessidade de uma atuação feminina, o que uma recolocação, onde a mulher é vista como acarretou no crescimento das contratações. indivíduo autônomo e independente, rompendo Ainda, com a evolução da mulher, esta com os padrões antigos que as limitavam os seus lugares de atuação.

passou a ocupar cargos que antes eram atribuídos aos homens. Pouco a pouco foi se desmistificando

Restringindo o papel feminino ao dever de a ideia de separação de funções no ambiente de ser mãe, esposa e dona de casa, nascia a submissão ao homem, que por muito tempo dominou as mulheres. Neste cenário, diante da ideia de muitos homens de que eram superiores às mulheres, desencadeava-se ainda a violência psicológica e muitas vezes, física.

O patriarcado não se resume a um sistema de dominação, modelado pela ideologia machista, [...] ele é também um sistema de exploração. Enquanto a dominação pode, para efeitos de análise, ser situada essencialmente nos campos político e ideológico, a exploração diz respeito diretamente ao terreno econômico (SAFFIOTI, 1987, p.18).

A opressão machista difundiu na sociedade a ideia de incapacidade da mulher de exercer funções que antes eram consideradas exclusivas para o homem. No mercado de trabalho, houve, após muitas lutas, sistemas e mecanismos de proteção ao trabalho feminino.

No entanto, a proteção acabou por refletir em um resultado oposto do pretendido, visto que, ao proteger demasiadamente a mulher, não se incentivava a inserção da mesma no ambiente de trabalho, além de causar receios nos empregadores pelo excesso de garantias de que seriam as empregadas detentoras.

trabalho e na sociedade que antes eram determinadas pelo sexo. "A sociedade delimita com bastante precisão, os campos em que pode operar a mulher, da mesma forma como escolhe os terrenos em que pode atuar o homem" (SAFIOTTI, 1988, p. 8).

Em linhas gerais, as conquistas obtidas com os movimentos feministas se referem às lutas para coibir de todas as formas as violências de gênero sofridas. Não se trata apenas de erradicar as agressões físicas ou morais que por muito tempo foram suportadas. O preconceito sofrido é violência velada, que, para muitos é considerado simplesmente algo cultural, relacionado com a maneira em que fomos criados.

Ser reconhecida como uma mulher é afirmar uma experiência diferente, uma percepção diferente da realidade, enraizada em "outro" corpo, numa maneira específica de se relacionar com a pessoa. O movimento de mulheres, quando fala de diferença, fala para o conjunto da sociedade e não apenas para as mulheres. Para as sociedades que desenvolvem uma pressão crescente pela conformidade, esta reivindicação tem efeitos disruptivos, desafia a lógica do sistema e tem uma orientação antagonista. O resultado político do

Para Neves (2000), a ascensão da mulher se movimento de mulheres em termos de igualdade deu em 1970 com o crescimento do mercado de permite que a diferença seja reconhecida. Mas o 
"êxito" no campo político enfraquece o movimento, aumenta sua segmentação, leva alguns grupos à profissionalização e à burocratização, e outros a um sectarismo disruptivo. A mensagem da diferença, entretanto, não morre. Torna-se um objetivo cultural e político que mobiliza muitos outros grupos (MELUCCI, 1989, p. 10).

Neste contexto, o reconhecimento da mulher como sujeito capaz na mesma proporção dos homens, aos poucos, começa a romper com os preceitos históricos de inferioridade que era atribuído a figura feminina.

Para Aristóteles (1991) em todas as espécies o macho sempre foi considerado superior à fêmea. No âmbito familiar, no que tange à divisão de poderes essa superioridade se mantem. Culturalmente, se fez a ideia de que o poder de um homem se mostra na capacidade de se impor, revisto.

enquanto para a mulher resta a tarefa de obedecer.

$$
\text { Para Bourdieu (1999) as relações e a }
$$
estrutura de dominação se explicam na questão de gênero, que constituem as ligações de poder, onde o masculino é tomado como base para todas as coisas. Para o autor a reprodução dessa diferenciação se perpetuou através da família que impõe as divisões sexuais do trabalho; na igreja construída sob uma moral familiarista e absolutamente patriarcal; e na escola, onde se delimitava a homem/mulher suas próprias faculdades, especialidades e aptidões.

A cultura de uma sociedade patriarcal torna a figura da mulher delimitada a atividades domésticas, trazendo ao homem o dever de provimento e sustento da casa. O principal problema deste modelo são os estereótipos dos sexos, o que dá ênfase e força ao preconceito.
A temperança e a justiça diferem até entre pessoas livres, das quais uma é superior e a outra inferior, por exemplo, entre o homem e a mulher. A coragem de um homem se aproximaria da pusilanimidade se fosse apenas igual à de uma mulher, e a mulher passaria por atrevida se não fosse mais reservada do que um homem em suas palavras (ARISTÓTELES, 1991, p. 44)

Logo, a cultura das sociedades impôs desde cedo distinções especificas a se manter entre homem e mulher. No entanto, até que ponto os aspectos ditos como culturais podem ditar as regras de uma sociedade? As conquistas alcançadas e principalmente aquelas que ainda se buscam, se referem à ruptura dos padrões que foram impostos, do senso moral que foi construído por uma sociedade machista e que precisa urgentemente ser

Elementos conceituais e

históricos do feminismo

Vivemos um novo momento em nossa sociedade em que cada vez mais escutamos a respeito dos movimentos feministas, empoderamento das mulheres, igualdade de gênero e afins. Mas afinal, o que é o feminismo?

O feminismo é definido como um "movimento social cuja finalidade é a equiparação dos sexos relativamente ao exercício dos direitos civis e políticos" (OLIVEIRA, 1996, p.424). Não se trata de uma busca por dominação de um gênero sobre outro, mas sim, sobre a equidade entre eles. Segundo Pintassilgo (1981, p. 12), o feminismo é:

[...] a denúncia e a luta contra as práticas sexistas [...] isto é, as atitudes, práticas, hábitos e, 
em muitos casos, a própria legislação, que fazem das pessoas pertencentes a um sexo, e só por esta razão, seres humanos inferiores nos seus direitos, na sua liberdade, no seu estatuto, na sua oportunidade relacional de intervenção na vida social.

Assim, os movimentos feministas surgem com a necessidade de discutir a respeito do papel da mulher na sociedade, assim como desconstruir as classificações sexistas impostas pela sociedade.

Assim, o feminismo coloca a opressão da mulher no centro de suas formulações, dando um estatuto teórico equivalente ao da exploração de classe, pois o poder é distribuído de maneira desigual entre os sexos, cabendo às mulheres uma posição subalterna na organização da vida social (SORJ, 1992, p. 16).

O feminismo surgiu então para questionar as relações de poder entre o homem e a mulher, buscando entender essa submissão. Desta forma, todo trabalho e embasamento de existência deste movimento se dá na busca de dirimir as questões atinentes ao gênero e a suas discriminações, além de explorar o controle patriarcal e suas interferências nas relações sociais com o único intuito de se chegar à erradicação das desigualdades ainda hoje existentes.

Segundo Oliveira (1996) o feminismo surgiu logo no final do século XVIII, advindo de uma construção da crítica que começou a surgir nesta época relacionada à submissão das mulheres em relação aos homens em vários aspectos sociais.

No cenário internacional, podemos perceber o destaque feminino na Revolução Francesa, quando homens e mulheres, aliados, reclamavam pela queda da monarquia defendendo a igualdade entre os povos, o que posteriormente se tornou o lema da França: Igualdade, Liberdade e Fraternidade, princípios essenciais que sintetizam a harmonia de uma sociedade (CARVALHO, 2004).

No Brasil, a ideologia feminista ganha espaço em diferentes classes sociais quando as mulheres se levantam reivindicando por direitos políticos até então não existentes, como por exemplo, o poder de participação nas eleições através do voto e da permissão a candidatura para cargos do poder executivo e legislativo.

Malgrado essa conquista, o direito alcançado era ainda limitado. Em 1932 o Código Eleitoral Provisório previa o direito ao exercício político apenas às mulheres casadas mediante autorização de seu marido e às mulheres solteiras e viúvas que tivessem renda própria (CARVALHO, 2004).

Ainda segundo o autor, somente alguns anos mais tarde, a mulher passou a gozar dos mesmos direitos dos homens, quanto à liberdade ao voto obrigatório, secreto e universal, e ao exercício político sem quaisquer distinção expressa com relação aos homens.

Na década de 70, a Organização das Nações Unidas (ONU) se preocupou em suas convenções de trazer à tona a questão da desigualdade de gênero. Em 1975, foi decretado o ano internacional da mulher, no qual buscou identificar e combater as causas que impediam o avanço da mesma na sociedade (CARVALHO, 2004).

Os movimentos feministas buscam atingir seus objetivos pressionando o Estado a repensar e gerar novas formas de institucionalização e de mediação com os interesses das mulheres. O diálogo destes movimentos propicia a criação de ambientes institucionais e políticas públicas que 
estão formalmente incumbidas de garantir os direitos das mulheres.

O feminismo questionou a clássica distinção entre o "dentro" e o "fora", o "privado" e o "público". O slogan do feminismo era: "O pessoal é político". Ele abriu, portanto, para a contestação política, arenas inteiramente novas de vida social: a culturais.

família, a sexualidade, o trabalho doméstico, a divisão doméstica do trabalho, o cuidado com as crianças etc. Ele também enfatizou, como questão política e social, o tema da forma como somos formados e produzidos como sujeitos generificados. Isto é, ele politizou a subjetividade, a identidade e o processo de identificação (como homens/mulheres, mães/pais, filhos/filhas) (HALL, 1997, p. 49).

Com o passar dos anos e diante de pequenas conquistas alcançadas, os movimentos feministas foram ganhando força e trazendo para si um olhar da sociedade e especialmente de outras mulheres que foram aos poucos reconhecendo a importância e a necessidade das reivindicações feitas, uma vez que os benefícios concedidos alcançavam a todas.

No entanto, segundo Carvalho (2004), durante o período ditatorial o movimento perdeu suas forças devido às intensas e violentas repressões a que foram submetidos toda a população, especialmente aquela parte que manifestava a tudo quanto era considerado injusto e desigual.

Neste interim, findado este período, a população novamente volta a ser ouvida e respeitada pelo poder público e novamente as mulheres reaparecem, dessa vez com mais força e usando a imprensa para propagar suas ideias e restabelecer seus direitos.
Em 1985 é criado o CNDM (Conselho Nacional dos Direitos da Mulher) que, segundo Miranda (2009) tinha como proposta, a divulgação em todo o país de politicas que propiciassem a mulher igualdade de direitos, liberdade e ampla participação nas atividades políticas, econômicas e culturais.

$\mathrm{Na}$ intenção de eliminar barreiras de preconceito e opressão contra as mulheres, o feminismo busca mais do que a igualdade, mas tem como foco o reconhecimento da sociedade quanto a diferença de gênero, e a necessidade de quebrar este paradigma.

É devido a diferenciais de poder entre homens e mulheres que as feministas têm-se referido às mulheres como uma minoria, mesmo que elas perfaçam mais da metade da população. [...] os eventos que determinam que minorias sejam minorias o fazem através da atribuição do status de minoria a algumas qualidades inerentes ao grupo minoritário, como se essas qualidades fossem a razão e também a racionalização de um tratamento desigual. Por exemplo, a maternidade foi frequentemente oferecida como explicação para a exclusão das mulheres da política, a raça como razão da escravização e/ou sujeição dos negros, quando de fato a relação de causalidade se dá ao inverso: processos de diferenciação social produzem exclusões e escravizações que são então justificadas em termos de biologia ou de raça (SCOTT, 2005, p.18-9).

A luta pela igualdade entre homens e mulheres vem percorrendo séculos, e pouco a pouco a mulher tem mostrado seu valor e sua capacidade de exercer sua cidadania da mesma forma que os homens, não sendo justificável 
qualquer oposição ou demérito pela simples condição de ser mulher.

Ainda dentro do feminismo, há outro lado do movimento denominado como feminismo negro. Com todas as discriminações e preconceitos enfrentados pela mulher, a mulher negra enfrenta tudo isso sob uma perspectiva muito maior.

Para Ribeiro (2015) o feminismo como vertente exclusiva une os gêneros, mas separa e distancia as especificidades raciais. Enquanto na segunda onda expressiva do movimento na década de 80 as mulheres brancas lutavam por direito a voto, inserção no mercado de trabalho e etc, as mulheres negras ainda lutavam pelo seu reconhecimento como ser humano.

O feminismo negro é fundamental para o reconhecimento da existência de várias mulheres numa única perspectiva de gênero. A questão racial não deve ser entendida como uma rixa as mulheres brancas, mas sim como forma de admitir os privilégios de que elas detém com relação as mulheres negras.

Não obstante aos preconceitos e opressões enfrentados pelas mulheres diante da sociedade, temos uma situação séria no país que tem se agravado nos últimos anos: o encarceramento feminino. Assim, conforme será demonstrado, o principal fator que desencadeou o aumento no número de mulheres encarceradas, se deve a política proibicionista de drogas existente, que dá forças a questão da seletividade penal.

\section{A política proibicionista de} drogas como instrumento das desigualdades de gênero
O consumo de substâncias tóxicas desde sempre foi alvo de inúmeras discussões e debates, uma vez que o uso indevido e indiscriminado destas traz transtornos, como por exemplo, a dependência física ou psicológica por parte daqueles que fazem tal uso.

A Organização Mundial de Saúde (1981) conceitua as substâncias psicoativas como:

substâncias psicoativas são aquelas que, quando consumidas ou administradas ao organismo, afetam processos mentais como cognição ou sentimentos. Essa expressão e sua equivalente, droga psicotrópica, são os mais neutros e descritivos termos para toda a classe de substâncias lícitas e ilícitas de interesse das políticas sobre drogas.

Assim, infere-se que as substâncias tóxicas, na realidade, sempre fizeram parte da sociedade, sendo utilizadas de diferentes formas, seja para tratamento de doenças ou mesmo como forma de simplesmente se obter sensações prazerosas ou alucinógenas.

Os chamados psicoativos estão incluídos dentro do rol de substâncias que alteram a função cerebral, de maneira que quando não são utilizados com intuito medicinal, quase sempre acabam por causar dependência, na medida em que este consumo vai se fazendo frequente.

No intuito de coibir essa prática desenfreada, conforme menciona Rodrigues (2004), o Brasil, após muitas décadas mantendo-se inerte, criou os primeiros métodos repressivos ao uso indiscriminado destas substâncias. Influenciado pelos meios utilizados por outros países no proibicionismo das drogas, o Brasil, por meio do Decreto e Lei n²4.294 de 06 de julho de 1921 
estabeleceu penalidades para os contraventores das substâncias entorpecentes mais comuns à época, como o ópio, cocaína e a morfina, além ainda, de trazer a possibilidade de internação pelo uso do álcool.

Mais tarde, a Lei de $\mathrm{n}^{\circ} 20.930$ de 11 de janeiro de 1932 normatizou a entrada e o comércio de substâncias tóxicas no país, onde mais tarde, com o advento do Código Penal de 1940, fora regulamentado como crime contra a saúde pública a comercialização de entorpecentes sem autorização ou em desacordo com determinação legal.

$\mathrm{Na}$ intenção de coibir o consumo e a comercialização destas substâncias, várias foram as legislações e resoluções criadas, onde pouco a pouco crescia o rol dos entorpecentes e aumentava as penas para aqueles que transgrediam essas normas.

Com a promulgação da Constituição Federal em 1988, fora incluído em seu artigo $5^{\circ}$ a equiparação do tráfico de drogas ao rol dos crimes hediondos, prevendo sua inafiançabilidade e inviabilizando qualquer possibilidade de anistia ou graça.

Malgrado a evolução da legislação brasileira no tocante as drogas, a normatização mais recente diz respeito à Lei $\mathrm{n}^{\circ} 11.343$ de 23 de agosto de 2006 que estabeleceu de forma definitiva o Sistema Nacional de Políticas Públicas Sobre Drogas (SISNAD) criando medidas preventivas, estabelecendo normas para a repressão ao tráfico ilícito de drogas, e ainda buscando atender os usuários e dependentes químicos, de forma a tratalos e reinseri-los na sociedade.
Neste interim, preceitua Gomes (2007, p.48) sobre os principais aspectos da Lei 11.343/06:

[...] (a) pretensão de se introduzir no Brasil uma sólida política de prevenção ao uso de drogas, de assistência e de reinserção social do usuário; (b) eliminação da pena de prisão ao usuário (ou seja: em relação a quem tem posse de droga para consumo pessoal); (c) rigor punitivo contra o traficante e financiador do tráfico; (d) clara distinção entre o traficante "profissional" e o traficante ocasional; (e) louvável clareza na configuração do rito procedimento e (f) inequívoco intuito de que sejam apreendidos, arrecadados e, quando o caso, leiloados os bens e vantagens obtidos com os delitos de drogas.

A partir de então, a repressão à prática do uso e consumo de drogas tornou-se mais severa. No entanto, contrário ao resultado pretendido, foi notório o fato de que, quanto mais se proibia, mais se consumia. Apesar da boa intenção, a nova Lei de tóxicos acabou por deixar em seu texto vários pontos controvertidos, o que desde sua decretação foi e é alvo de constantes equívocos no momento da interpretação e aplicação da lei aos casos concretos (GOMES, 2007).

Como fruto desse modelo proibicionista, no Brasil, a lei de tóxicos é hoje um reflexo da conjuntura política-repressiva absolutamente seletiva, decorrente de um parâmetro moralista que propôs desde seu surgimento, a erradicação do consumo/comercialização de psicotrópicos não apenas visando a saúde ou a segurança pública, mas na realidade, sempre foi pautada por interesses econômicos e políticos.

$$
\text { Segundo Rodrigues (2004) a doutrina }
$$


quais sejam: a práxis moralista, a saúde pública, a segurança pública, a segurança nacional e o proibicionismo militarista. De maneira direta, todos estes vetores apontam para uma das maiores crises no sistema penal brasileiro: o encarceramento em massa e a seletividade penal.

Neste interim, um dos pontos mais criticados no que se refere à lei 11.343/06, diz respeito ao texto do artigo $28, \mathbb{\$} 2^{\circ}$, in verbis:

$\int 2^{\circ}$ Para determinar se a droga destinavase a consumo pessoal, o juiz atenderá à natureza e à quantidade da substância apreendida, ao local e às condições em que se desenvolveu a ação, às circunstâncias sociais e pessoais, bem como à conduta e aos antecedentes do agente. (grifo próprio)

Conforme se extrai da própria lei, a mesma já tem em seu texto todo o cunho segregacionista, confirmando a preferência e pré-disposição dos escolhidos pelo sistema punitivo, que seleciona aquela parcela da população já considerada minoria, como os negros, os pobres e as mulheres, que ao longo da história foram marginalizados e tratados com completo descaso pela sociedade.

Em um cenário de opressão exercida pela sociedade, e de criminalização imediata imposta pelo Estado no campo das minorias, cria-se um importante embate a respeito do aumento do encarceramento feminino e a relação direta deste com o surgimento e advento da chamada lei de tóxicos.

Segundo dados das Informações Penitenciárias (INFOPEN) realizada no ano de 2014, estima-se que atualmente cerca de $25 \%$ da população carcerária masculina se dá em decorrência do crime do tráfico de drogas. Do outro lado, nas penitenciárias femininas, cerca de $67 \%$ estão reclusas pelo mesmo crime.

A proporção irregular do encarceramento feminino pela prática do narcotráfico revela a hipossuficiência da mulher inserida neste delito, onde, normalmente em seus antecedentes históricos revela os problemas sociais vividos por esta parcela da população que acaba sendo levada ao crime, como por exemplo, a baixa escolaridade, a falta de oportunidades de emprego e a atratividade e facilidade do mercado ilícito dos psicotrópicos.

O ritmo alarmante do encarceramento revela os velhos problemas enfrentados pelas mulheres: a submissão aos homens e a omissão do estado nas questões relativas as políticas públicas voltadas para o tratamento diferenciado das mulheres, reconhecendo a situação de vulnerabilidade destas em relação aos homens.

Sabe-se que, até mesmo pelo papel secundário que a mulher mantém na sociedade, essa associação ao tráfico, na grande maioria dos casos, não se dá de maneira espontânea, nem tão pouco, tendo a figura feminina como líder, ou chefe das grandes associações criminosas do tráfico ilícito de drogas.

Desta forma, mais uma vez fica demonstrado o retrato da realidade social nas diferenciações de gênero. Percebe-se que o sistema penal pretende ser operacionalizado nos limites da lei, a fim de garantir uma aplicação igualitária aos seus infratores. No entanto, os estudos demonstram que o sistema penal age de forma discriminatória e seletista, reproduzindo 
relações de opressão contidas nas relações sociais. (ANDRADE, 2003).

Assim, toda a opressão vivida pela mulher em todos os aspectos sociais como os já citados neste trabalho, se reflete também e principalmente no campo do Direito Penal e sua seletividade, revelando nos aspectos da criminologia a necessidade de uma política específica para o estudo da criminalidade feminina.

O sistema penal, em linhas gerais, mesmo quando se pretende a proteção da mulher, acaba por reproduzir e evidenciar ainda mais a desigualdade de gênero. Daí surge a necessidade do feminismo no estudo de uma criminologia crítica afim de buscar erradicar o sexismo presente na nossa legislação.

No que se trata da submissão aos homens, este fato só confirma um problema que se mantem desde o início das gerações, e que perpetua até os dias atuais: O patriarcado. A ideia da obediência e da dominação dos homens sobre as mulheres também se reflete na conjuntura da política atual de drogas e do crescente encarceramento feminino.

Para Costa (2008) o perfil das mulheres encarceradas se repete: classe baixa, negras, com filhos, sem antecedentes criminais, e grande parte delas em estado de reclusão por terem prestado favores a seus maridos ou companheiros, servindo de vendedoras, embaladoras ou entregadoras no mercado de drogas comandado pelos homens.

Outra situação extremamente comum trata dos inúmeros casos de mulheres que são presas no momento das visitas aos seus companheiros nos presídios por tentarem introduzir as substâncias aos seus maridos, companheiros ou parentes mais próximos.

Todo o contexto facilitador da mulher na entrada e atuação no narcotráfico revela a falta de oportunidades nos empregos formais, além das desigualdades de gênero presentes, já que, em qualquer área em que a mulher atue, a mesma sempre está em pé de desigualdade e inferioridade com relação ao homem.

Como apresenta CHAVARRIA (2008, p. 43-44), estas mulheres acabam por estarem também presas aos estereótipos criados pela sociedade:

no entanto, estas representações limitam a compreensão do fenômeno das mulheres dentro do tráfico de drogas e o polarizam. Por um lado se identifica estas mulheres como mães desinteressadas, despreocupadas pelos cuidados de seus filhos, ingênuas e débeis por se deixarem manipular por um homem que as engana e as utiliza para seus negócios ilícitos e onde elas não têm poder de decisão. Em outro extremo estão as mulheres identificadas como problemáticas, aquelas que em razão de seu vício não logram materializar as oportunidades que a sociedade lhes oferece, mães más, prostitutas, ladras e responsáveis por seu próprio destino. Ambas posturas complicam a compreensão integral do fenômeno e delimitam as soluções do problema ao não integrarem em suas análises os diferentes fatores que intervém em cada caso e como é necessário compreender a interação entre aspectos estruturais e situações particulares.

A motivação dessas mulheres que são levadas ao crime não está atrelada apenas à necessidade de dinheiro e falta de oportunidades, 
mas de fato, à influência que seus companheiros exercem sobre si, acaba por se tornar um importante condutor, senão o principal deles ao induzimento da mulher no tráfico. O que é demonstrado por Costa (2008), a motivação dessas mulheres que se tornam traficantes se dá por múltiplos fatores, tais como as relações íntimo-afetivas, para dar alguma prova de amor ao companheiro, pai, tio etc., ou, muitas vezes, por se envolverem com os traficantes inicialmente como usuárias, com o propósito de obter drogas, onde então, acabam em um relacionamento afetivo que as conduz ao tráfico.

Outro fator motivador das mulheres que se encontram inseridas no tráfico, é o status que estas adquirem e o destaque em relação as outras mulheres, por acreditarem que uma vez envolvidas na traficância, acabam por ganhar certo reconhecimento dos homens, não de forma a equiparar-se a eles, mas ao menos por se sobreporem as demais mulheres.

De maneira geral, é certo que mesmo inseridas no tráfico, essas mulheres não atuam de maneira protagonista, já que este papel é sempre exercido pelo homem que mantem o comando de todas as operações. Assim, a mulher exerce um papel coadjuvante, sendo a figura por trás dos chefes, em posições subordinadas aos homens.

Todo o poder envolto no tráfico de drogas pertence aos homens. Toda a lucratividade advinda deste comércio ilícito recai sobre os homens. A mulher mantem a posição desprestigiada de estar em segundo plano tanto no exercício da atividade, quando nos rendimentos advindos dela.
Desta forma, a participação feminina no narcotráfico também é secundária. Mesmo atuando como ajudantes de seus companheiros, esta, no momento em que é julgada pelo crime, recebe a mesma pena que aqueles que realmente estão no comando das operações.

O legislador ao prever a Lei $\mathrm{n}^{\circ} 11.343 / 06$, não identificou em nenhum momento que existe uma diferença absurda de atuação e participação entre a mulher e o homem que comete o crime previsto em seu artigo 33. Além disso, basta uma análise aos casos concretos e podemos facilmente identificar uma evidente vulnerabilidade $\mathrm{da}$ mulher com relação ao homem.

O que ocorre na realidade, é que as posições ocupadas pelas mulheres no tráfico ficam em segundo plano com relação ao prestígio e ao dinheiro que se é obtido, porém, devido aos papéis desempenhados por elas, como, por exemplo, "bucha" (pessoa que é presa por estar presente na cena em que são efetuadas outras prisões), consumidoras, "mula" ou negociantes de pequenas quantidades no varejo, cúmplices, e etc., é que estas acabam sendo a parte atrativa do crime, sendo então vistas primeiro pela polícia, o que leva a prisão.

Desta forma, enquanto os homens comandam todos os planos e operações, as mulheres, em submissão a eles, se encarregam de executar as tarefas mais arriscadas, para que os estes não corram tanto risco e continuem mantendo a liderança e as vantagens obtidas do tráfico.

Diante desta hierarquização existente na comercialização de substâncias ilícitas, é fundamental $\mathrm{O}$ reconhecimento $\mathrm{da}$ 
hipossuficiência da mulher que participa dessa atividade, haja vista, as ocupações exercidas por elas, bem como a facilidade em se perceber que esse envolvimento ao tráfico acontece pela influência do homem sobre a mulher.

Não se trata de isentar a mulher de qualquer culpabilidade, ou isenta-la de pena, mas sim, de reconhecer que, mesmo tipificados em um mesmo crime, na grande maioria das vezes as mulheres estão sim em relação de indefensibilidade quando comparadas aos homens, por todas as circunstâncias que envolvem essas mulheres, como a pobreza extrema, a falta de oportunidades que ainda é latente para estas, a dependência psicológica e econômica, a vulnerabilidade, a coerção e a própria opressão sofrida.

Assim, o que se faz necessário, é a inserção da perspectiva de gênero na Lei $\mathrm{n}^{\circ} 11.343 / 06$, afim de resguardar os direitos da mulher. Não se trata de formalizar um tratamento especial pelo fato de ser mulher, mas de legitimar que a máxima dos direitos iguais deve ser interpretada dentro das desigualdades de cada um, o que gera a necessidade de tratamento específico para o julgamento e processamento de mulheres acusadas por tráfico de entorpecentes.

Desta forma, o próximo capítulo tratará dos reflexos gerados pela lei de drogas, trazendo estatísticas que apontam para a confirmação do problema sobre o encarceramento feminino em massa, demonstrando as falhas da política proibicionista de drogas, e ainda, como a seletividade penal existente fortalece a discriminação de gênero.

\section{Um retrato do encarceramento}

\section{feminino no Brasil}

As mulheres condenadas hoje pelo crime de tráfico de drogas possui um perfil peculiar, que demonstra o preconceito ainda latente em nossa sociedade. A partir dos dados que serão demonstrados, será traçado o perfil dessas mulheres, bem como todos os fatores de risco a que são expostas no momento do cárcere.

Conforme gráficos da pesquisa realizada a pedido do Ministério da Justiça pelo INFOPEN divulgadas no ano de 2015, foi constatado o que já se fazia ideia. Segundo a pesquisa, entre o ano 2000 e 2014 houve um crescimento de 567\% na população de mulheres encarceradas enquanto $220 \%$ de aumento da população masculina.

Diante do histórico de violências de todos os tipos sofridos pela mulher, o encarceramento revela mais uma das faces dessa violência, evidenciando em seu sistema todos os abusos, humilhações e descaso do poder público no tratamento destas.

Existem diferenças essenciais entre homens e mulheres que devem ser observadas no contexto social, não de uma forma a elevar um em detrimento de outro, mas de maneira a reconhecer as peculiaridades de cada gênero, de modo que se possa garantir o tratamento adequado a cada um.

No contexto criminológico, como já visto, as mulheres são culturalmente e juridicamente os alvos mais fáceis do sistema penal. Uma vez adentradas neste sistema acabam se mantendo sob o controle estatal, mas nunca sob a proteção deste. 
Inegavelmente a participação feminina no crime é inferior à dos homens. No entanto, o fato a que se deve maior destaque, diz respeito ao crescimento absurdamente elevado das mulheres no ingresso às penitenciárias.

\section{Evolução da população de mulheres no sistema penitenciário. Brasil. 2000 a 2014}

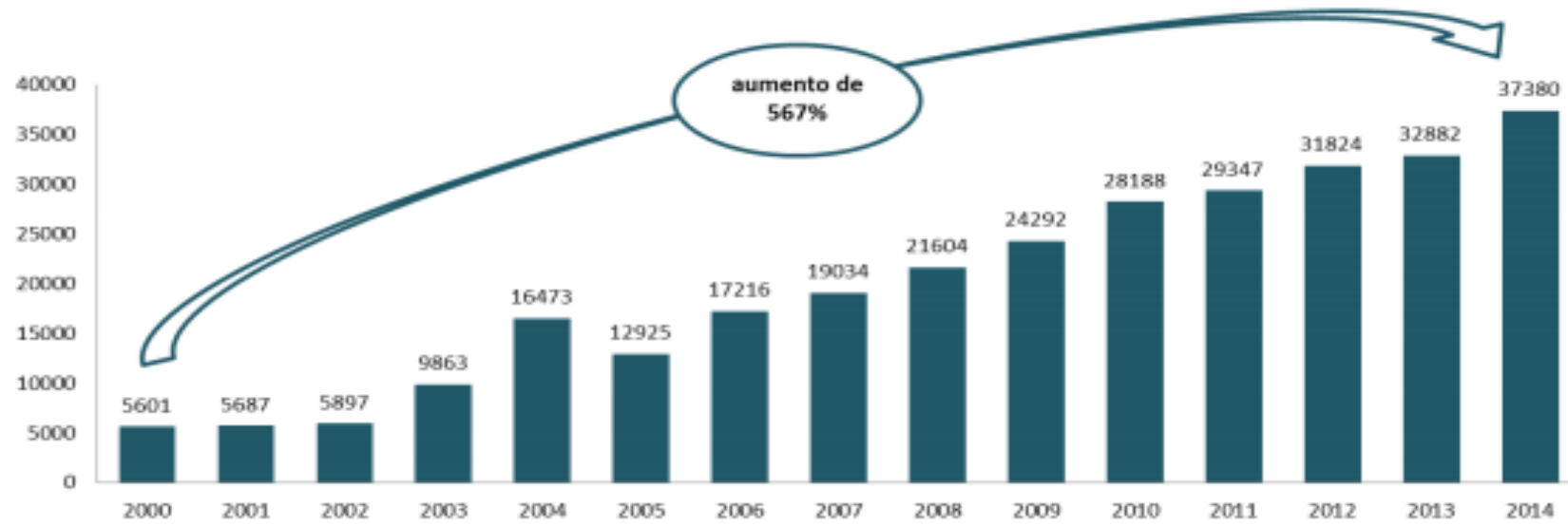

Fonte: Ministério da Justiça - a partir de 2005, dados do Infopen/MJ.

Diante do aumento alarmante nos últimos anos, é fundamental entender os possíveis fatores que desencadearam o crescimento da população feminina nos presídios. Assim, conforme o levantamento de dados realizado pelo INFOPEN entende-se que grande parte desse encarceramento se justifica pela falha política proibicionista de drogas existente hoje no Brasil, representada pela Lei 11.343/06.

Ainda conforme comprovam os dados, grande parte dessas mulheres se encontram reclusas em decorrência do crime de tráfico de drogas, com uma grande disparidade em relação aos outros crimes.

Distribuição por gênero dos crimes tentados/consumados entre os registros das pessoas privadas de liberdade. Brasil. Junho de 2014
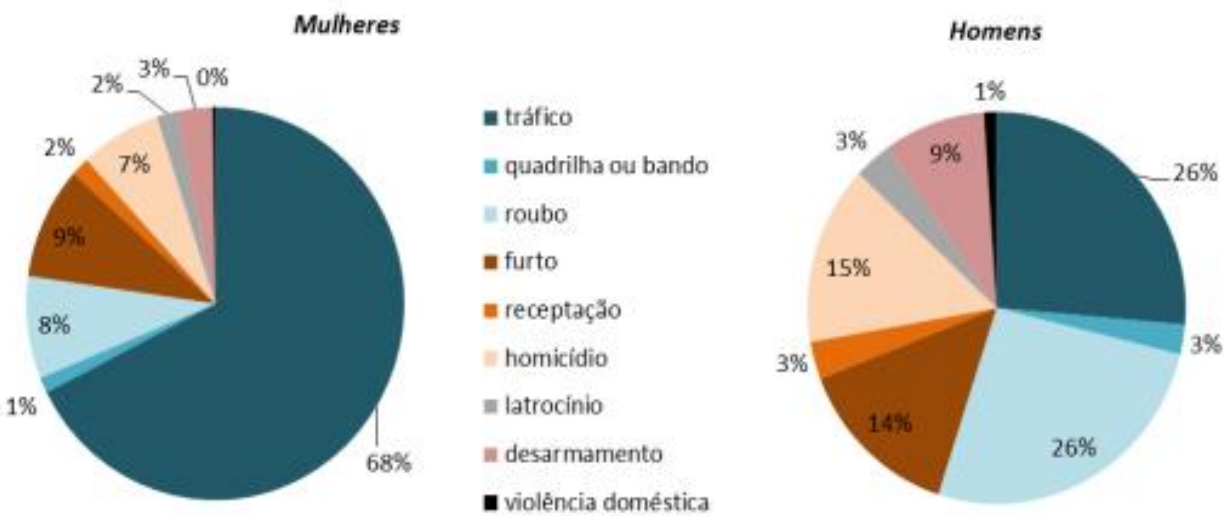

Fonte: Infopen, jun/2014. Departamento Penitenciário Nacional/Ministério da Justiça. 
Verificou-se também que a maioria dessas mulheres não ocupam posição de comando nas organizações criminosas e não se dedicam a essas atividades. Conforme se extrai do gráfico acima, a Lei de Tóxicos é a que mais encarcera mulheres no Brasil.

Em comparativo, o crime que mais detêm as mulheres aparece de maneira muito inferior em relação aos homens. Estes estão reclusos em sua grande maioria pelo crime de roubo, furto, homicídio dentre outros. Contrário à condição das penitenciárias femininas, que mantem o maior número de encarceramento em decorrência do tráfico de drogas.

Neste encarceramento em massa de

\section{Raça, cor ou etnia das mulheres privadas de liberdade. Brasil. Junho de} 2014

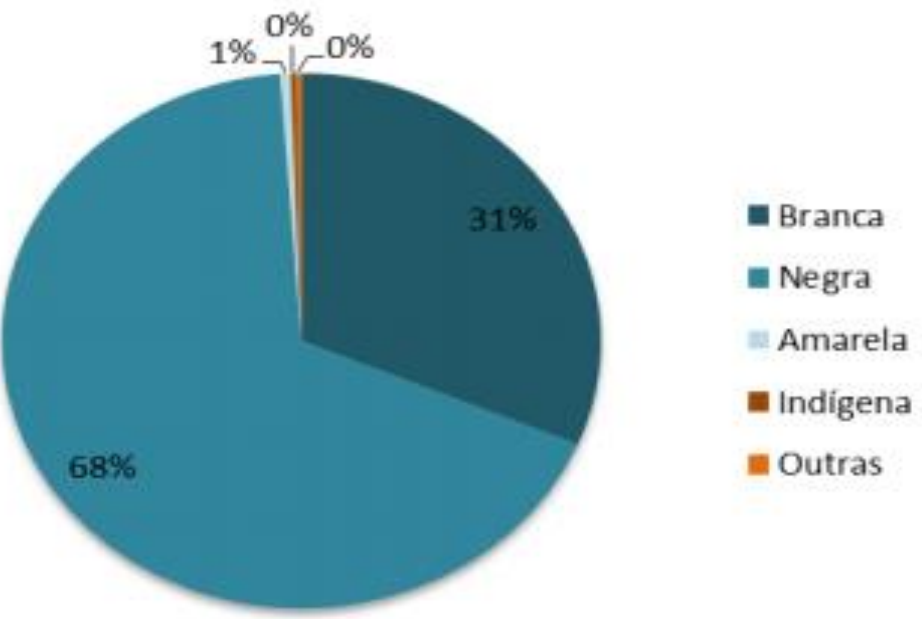

Fonte: Infopen, jun/2014. Departamento Penitenciário Nacional/Ministério da Justiça

Essas mulheres normalmente ocupam a camada mais baixa da sociedade, possuem pouquíssimas oportunidades de trabalho em razão da baixa escolaridade e quando trabalham geralmente ocupam cargos informais, desprestigiados e com baixa remuneração. mulheres em virtude do tráfico de entorpecentes, tem-se a realidade de mulheres acometíveis das mais diversas discriminações e que ocupam um interesse secundário por parte dos traficantes no auxílio do preparo e comercialização das drogas.

Diante da necessidade de traçar um perfil dessa mulher encarcerada, o INFOPEN constatou que o retrato dessas mulheres revelam a realidade social do público normalmente "escolhido" pelo sistema penal. Percebe-se então que essas mulheres presas se encontram naquela parcela da população que já é marginalizada pela sociedade, Estado e Poder Público. 


\section{Escolaridade das mulheres privadas de liberdade. Brasil. Junho} de 2014

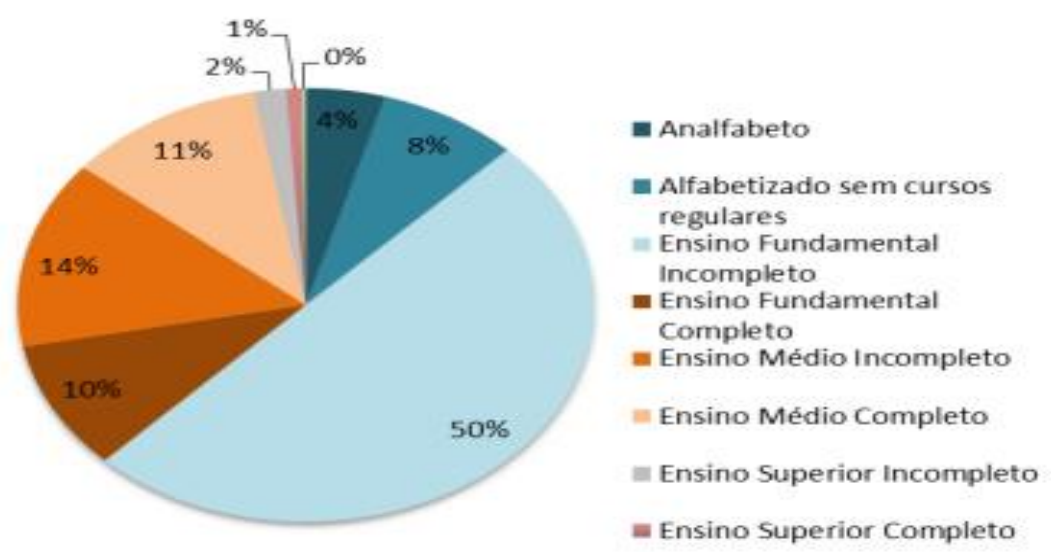

Fonte: Infopen, jun/2014. Departamento Penitenciário Nacional/Ministério da Justiça.

Ainda, a superlotação existente hoje nos presídios acaba por submeter os presos a situações devastadoras decorrentes deste abarrotamento carcerário, como a disseminação de doenças infectocontagiosas, falta de segurança, rebeliões e etc.

Os problemas causados pelo cárcere atingem de maneira direta os presos submetidos a este complexo. O ideal de sistema regenerativo proposto pela Constituição e Código Penal no que tange ao procedimento punitivo/reabilitativo dos presos acabam não atingindo sua perspectiva, e ainda gerando efeito totalmente contrário do pretendido, já que aqueles que adentram a realidade das penitenciárias no Brasil se deparam com uma realidade tão assombrosa que tem seu estado psicológico infectado por essa condição.

Quanto as mulheres, estas sofrem todos estes reflexos do brutal sistema carcerário, devido às necessidades e especialidades de que precisam pela condição de ser mulher e que não são garantidas pelo poder Estatal. A mulher encarcerada é tratada de forma subalterna, não existindo uma diferenciação e um reconhecimento das peculiaridades que implicam sua condição.

Sendo assim, uma vez reclusa, o afastamento e a separação que ocorrem entre a mulher e a sociedade em geral, consolida as suas estigmas sofridas, e aumentam o olhar de repúdio da comunidade por não aceitar uma mulher presa, já que condicionam que a mulher que deveria se dedicar as funções do lar, aos filhos, marido, etc. Conforme conceitua Castilho (2007, p. 38), apud GARCIA:

...a prisão para a mulher é um espaço discriminador e opressivo, que se expressa na aberta desigualdade do tratamento que recebe, no sentido diferente que a prisão tem para ela, nas consequências para sua família, na forma como o Judiciário reage em face do desvio feminino e na concepção que a sociedade atribui ao desvio. 
Desta forma, se os aspectos discriminatórios e repressivos que ocorrem com relação às pessoas encarceradas são grandes, quando se trata especificamente da mulher, essas situações são ainda mais graves, por todas as circunstâncias de prejulgamento em que sempre estiveram submetidas.

No que tange às dificuldades enfrentadas pelas mulheres no cárcere, além das citadas acima, se refere a questão da maternidade nos presídios. A Lei nº 7.210 de 11 de julho de 1984 denominada Lei de Execuções Penais (LEP) prevê em seus dispositivos a necessidade e a garantia de um tratamento especial às mulheres, principalmente mães, sendo que estas devem ser recolhidas em estabelecimento penal próprio, reconhecidas e adequadas a sua condição pessoal.

Sendo assim, é garantido que seja destinado a todos os estabelecimentos que abrigam mulheres os devidos cuidados desde a gravidez ao momento do nascimento da criança, sendo garantido tratamento médico, berçários e creches.

"Art. 14: \ 30 Será assegurado acompanhamento médico à mulher, principalmente no pré-natal e no pós-parto, extensivo ao recém-nascido."

"Art. 82: $\int 1^{\circ}$ A mulher e o maior de sessenta anos, separadamente, serão recolhidos a estabelecimento próprio e adequado à sua condição pessoal."
'Art. 83: $\int 1^{\circ}$ A mulher e o maior de sessenta anos, separadamente, serão recolhidos a estabelecimento próprio e adequado à sua condição pessoal.”

Com o levantamento da pesquisa realizada pelo INFOPEN, restou constatado que, na prática, todas essas garantias não se concretizam. Segundo os dados, nas unidades femininas apenas 32\% dispõe de berçários para os recémnascidos. Nas unidades mistas, o número cai para 3\%. Diante de tudo isso se tem ainda que das penitenciárias que oferecem estes berçários, a maioria tem um suporte muito aquém daquilo que deveria ser oferecido.

A Constituição Federal prevê em seu art. $5^{\circ}$, inciso L que: "às presidiárias serão asseguradas condições para que possam permanecer com seus filhos durante o período de amamentação". As garantias previstas destoam com a realidade. Sabese que hoje, quando as unidades penitenciárias asseguram a permanência dos filhos menores com a mãe, o fazem de maneira indevida.

No que diz respeito às creches nas penitenciárias, tem-se outra violação dos direitos assegurados as mulheres na LEP, já que tal garantia na realidade fática não ocorre, como visto no gráfico abaixo, apenas $5 \%$ das unidades atende a essa necessidade. 


\section{Existência de creche em unidades femininas e mistas. Brasil. Junho de 2014}

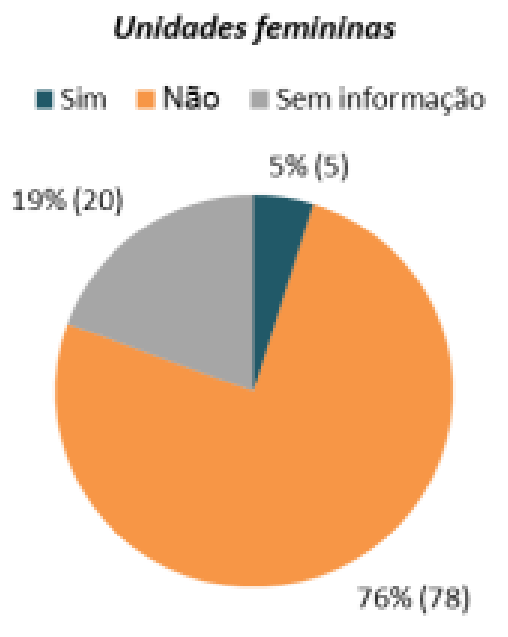

"Art. 89. Além dos requisitos referidos no art. 88, a penitenciária de mulheres será dotada de seção para gestante e parturiente e de creche para abrigar crianças maiores de 6 (seis) meses e menores de 7 (sete) anos, com a finalidade de assistir a criança desamparada cuja responsável estiver presa

Parágrafo único. São requisitos básicos da seção e da creche referidas neste artigo:

I - atendimento por pessoal qualificado, de acordo com as diretrizes adotadas pela legislação educacional e em unidades autônomas; e

II - horário de funcionamento que garanta a melhor assistência à criança e à sua responsável.”

Desta forma temos que, tal situação submete a mulher a uma punição maior do que a própria condenação penal sofrida, já que acabam por sujeitar essas mães a se afastarem de seus filhos, deixando-os aos cuidados e avós, vizinhos

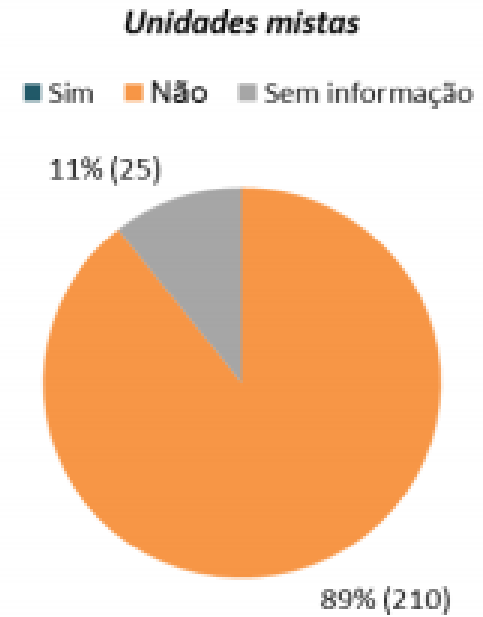

ou familiares ${ }^{1}$, o que torna essa ruptura familiar ainda mais traumática.

Diferentemente acontece com relação ao encarceramento masculino, que no cumprimento de suas penas, os homens normalmente nunca são deixados, recebem visitas de suas esposas/companheiras, dos filhos, tendo um suporte muito maior da família e do próprio poder judiciário.

A omissão do Estado quanto a mulher presa vai além das penas impostas, mas se sobreleva as condições degradantes e insalubres a que são expostas nas cadeias, as limitações abusivas de visitas, a falta de cuidados essenciais à saúde, principalmente quando estão grávidas, e ainda na falha do sistema ressocializador que busca inserir a mulher egressa de volta a sociedade.

\footnotetext{
${ }^{1}$ Nessas condições, a maioria dos pais não são presentes, o que acaba por ocasionar crianças que não possui uma educação familiar adequada, tornando-se comum o abandono a escola e em alguns casos a entrada para o mundo do crime, pela condição de desestrutura familiar.
} 
Uma vez expostas ao sistema, a mulher que já é mais vulnerável em tantos aspectos sociais, fica à mercê das inúmeras mazelas das femininas. penitenciárias, já que as políticas públicas para

\section{Existência de berçário e/ou centro de referência em unidades femininas e mistas. Brasil. Junho de 2014}

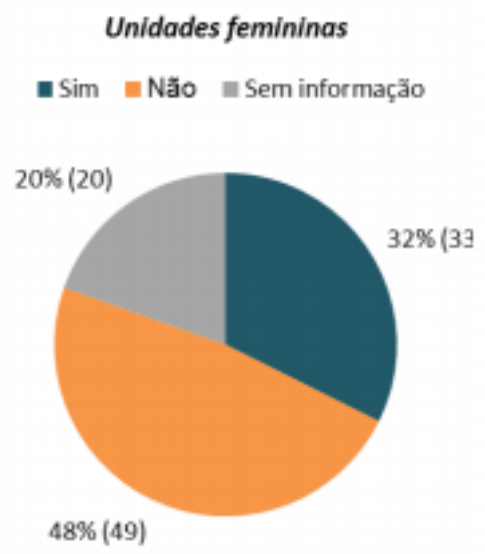

Os dados alarmantes colhidos pelo INFOPEN revelam a situação extrema de insalubridade e a exposição das mulheres encarceradas a doenças graves, que não são controladas e o Estado necessita estabelecer intervenções com políticas que busquem reverter este quadro. estes estabelecimentos são extremamente limitadas e incapazes de tratar das particularidades 
Sendo assim, se verifica que o cárcere feminino vai muito além da privação da liberdade. Se de um lado temos uma sociedade machista, opressora, que naturalmente "prende" a mulher, sujeitando-as ao controle dos homens, do outro lado, temos um sistema penal seletista e discriminador que acentua e dá forças à desigualdade de gênero presente na nossa sociedade.

\section{CONSIDERAÇÕES FINAIS}

Ao longo dos anos, a opressão da mulher na sociedade se evidenciou pela discriminação sofrida, subestimação da sua capacidade como se fossem inferiores ao homem apenas pela condição de ser mulher, o que foi fator essencial para propagar a desigualdade de gênero.

No primeiro tópico, verificamos que a figura do homem como líder da família compactuou com o contrato familiar, o que manteve durante séculos, a dominação do homem sobre a mulher, que carregou o peso das violências simbólicas sofridas no âmbito familiar e na sociedade. Assim, com a insatisfação de muitas mulheres, surgiram os movimentos feministas na intenção de romper com essa dominação e alcançar seus devidos direitos sociais e políticos, buscando romper com o patriarcado estabelecido por uma sociedade machista.

As reivindicações procuravam além da equiparação de direitos entre homens e mulheres, o reconhecimento da capacidade da mulher de exercer qualquer função que antes era considerada exclusiva para homens. Neste sentido, aos poucos se deu início a ruptura do referencial da mulher como ser inferior ao homem.

No segundo tópico, tratamos da questão da política proibicionista de drogas no Brasil e como seus resultados são deficientes no que tange a intenção de coibir o consumo e comércio das substâncias ilícitas. Desta forma, se verificou também que tal política acaba por colaborar ainda mais com a seletividade do sistema penal, já que no próprio corpo da lei se percebe que as características que diferenciam o usuário dos traficantes são datadas pelas questões sociais, raciais e de gênero.

O proibicionismo existente hoje não atinge os resultados pretendidos e ainda, no que tange à seletividade na esfera de gênero, acaba prendendo mulheres (em sua grande maioria) pelo crime de tráfico, sendo estas primárias no mundo do crime, e que geralmente se submetem a tal situação de maneira secundária, atuando em pequenas funções nos "bastidores" do tráfico, sendo sempre o alvo mais fácil da justiça.

No terceiro tópico, procuramos traçar o perfil das mulheres que vivem hoje no cárcere, e todas as dificuldades enfrentadas por elas na falta de atenção e zelo por parte do poder público com relação aos cuidados de que necessitam.

Percebemos que existe um descaso específico com as mulheres presas, além de uma constante violação de direitos, já que, as previsões em lei que garantem a existência de berçários, creches, cuidados médicos específicos à saúde da mulher, na realidade são constantemente violadas, ou oferecidas de maneira precária e ineficiente. 
Assim, dada à condição do encarceramento, a mulher privada de sua liberdade é duplamente punida, pois sua condenação vai muito além do cárcere, atingindo importantes aspectos como à sujeição às mazelas existentes nas penitenciárias, à exposição a vários tipos de doenças, o repúdio da sociedade, a ruptura dos laços familiares, além da dificuldade de ressocialização ao convívio social.

Contudo, é necessário que o sistema penal e a criminologia sejam repensados com relação às questões de gênero, dada a vulnerabilidade da mulher, o que clama por uma perspectiva feminista no intuito de garantir a aplicabilidade e eficácia das leis existentes na luta pela igualdade e erradicação das discriminações.

\section{REFERÊNCIAS BIBLIOGRÁFICAS}

ANDRADE. francisco leal de. DETERMINISMO BIOLÓGICO E QUESTÕES DE GÊNERO NO CONTEXTO DO ENSINO DA BIOLOGIA: representações e práticas de docentes do Ensino Médio. Salvador. 2011.

ANDRADE. vera regina. Cidadania: do direito aos direitos humanos. São Paulo: Acadêmica, 1993.

ANTUNES. Adeus ao trabalho?: ensaios sobre as metamorfoses e a centralidade do mundo do trabalho. São Paulo: Editora Cortez, 1997.

ARISTÓTELES. A Política. $1^{\circ}$ ed - São Paulo: 1991.

BEM. arim soares do. A centralidade dos movimentos sociais na articulação entre o Estado e a sociedade brasileira nos séculos XIX e XX. Educ.

Soc. Campinas, v. 27, n. 97, set/dez. 2006.
BOURDIEU. pierre. A dominação masculina. Rio de Janeiro: Editora Bertrand Brasil: 2012.

CARVALHO. josé murilo. Cidadania no Brasil: o longo caminho. 5. ed. Rio de Janeiro: Civilização Brasileira, 2004.

CASTILHO. ela wiecko v. de. Execução da pena privativa de liberdade para mulheres: a urgência de regime especial. Justitia, São Paulo, n. 64, jul./dez. 2007.

CEJIL; AJD; ITCC; CNBB; IDDD; Centro Dandara de Promotoras Legais Popular; ASBRAD; CTV; IBCCRIM. Relatório sobre mulheres encarceradas no Brasil. Fev. 2017.

CHAVARRIA. Eugenia Mata. Análisis de los condicionantes de vulnerabilidad em la mujer privada de libertad sentenciada por la Ley Sobre Estupefacientes, Sustancias Psicotrópicas, Drogas de Uso no Autorizado, Legitimación de Capitales y Actividades Conexas (Ley $\mathbf{N}^{\mathbf{0}}$ 8204) en Costa Rica. Universidad para la cooperación internacional, 2008.

CHRISTO. carlos alberto. Marcas de Baton. Revista Caros Amigos, 2001.

COSTA. elaine cristina pimentel. Amor bandido: as teias afetivas que envolvem a mulher ao tráfico de drogas. Maceió: ed. Edufal, 2008.

COSTA. ana alice a. $\mathbf{O}$ movimento feminista no Brasil: dinâmicas de uma intervenção política. Labrys Estudos Feministas, Jan/Jul, 2005.

DEL OLMO. rosa. A legislação no contexto das intervenções globais sobre drogas. Discursos Sediciosos: crime, direito e sociedade, Rio de Janeiro, v. 7, n. 12, 2002.

GOMES. luiz flávio. Lei de Drogas Comentada artigo por artigo: Lei 11.343/06, de 23.08.2006. $2^{\circ}$ ed. São Paulo: Revista dos Tribunais: 2007. 
HALL. stuart. A identidade cultural na pósmodernidade. $7^{\circ}$ ed. Rio de Janeiro: DP\&A, 2002.

Maria Shiver, The Shiver Report: A Woman's Nation Changes Everything. Washington D.C.: Center for American Progress, 2009.

MELUCCI. a. Movimentos sociais: questões conceituais. Lua Nova: Revista de Cultura e Política, ISSN 0102-6445, no.17 São Paulo, June, 1989.

MIRANDA. cynthia mara. Os movimentos feministas e a construção de espaços institucionais para a garantia dos direitos das mulheres no Brasil e no Canadá. Interfaces Brasil. v.15, n.1, 2015

OLIVEIRA. a. Feminismo. Enciclopédia LusoBrasileira. Lisboa: Verbo, 1996.

PATEMAN. Carole. O Contrato Sexual. Rio de Janeiro: Paz e Terra, 1993.

PINTASSILGO. Maria de Lourdes. Feminismo e Discurso do Gênero na Psicologia
Social. São Paulo: Associação Brasileira de Psicologia Social - ABRAPSO. 1981.

RIBEIRO. Djamila. Quem tem medo do feminismo negro. Disponível em: http://lugardemulher.com.br/quem-temmedo-do-feminismo-negro/

RODRIGUES. thiago. Política e drogas nas Américas. São Paulo: Educ - Fapesp, 2004.

ROSSEAU. Jean-Jacques. Do contrato social. Ed. Ridendo Castigat Mores, 2002.

SAFFIOTI. heleieth. O Poder do Macho. São Paulo: Editora Moderna, 1988.

SORJ. Bila. O feminismo na encruzilhada da modernidade e pós-modernidade. In: COSTA, Albertina; BRUSCHINI, Cristina. Uma questão de gênero. Rio de Janeiro: Rosa dos Tempos, 1992.

SCOTT. Joan. O enigma da igualdade. Florianópolis: Revista de estudos feministas, 2005. 